\title{
1. Planetary terra incognita
}

The year 2016 will be critical for the history of planet Earth. This is the year when the International Geological Congress will meet to finally settle the debate of whether humanity formally has entered a new geological epoch: the Anthropocene. This might seem like a superfluous subject for a scientific meeting to discuss considering the explosion of the concept in current policy and scientific debates. Not only did The Economist and National Geographic already in May 2011 produce special issues on this new era; in 2012, the British Broadcasting Corporation (BBC) broadcasted a series of documentaries on the 'human epoch', and publishing giant Elsevier inaugurated the new journal Anthropocene in 2013. Yet, the scientific debate has not been settled. And similarly contested concepts attempting to define humanity's impact on Earth - such as 'the great acceleration' and 'planetary boundaries' - are widely circulated amongst academics, concerned non-governmental organizations and policy-makers.

Any institutional and political analysis of global environmental change on a human-dominated planet, should build on a firm understanding of these concepts and their associated scientific and political debates. As I will elaborate, these disputes are becoming increasingly intense and difficult for outsiders to grapple. The reason I believe is simple: as research insights from the Earth system sciences gradually propagate through media and policy discussions, they renew existing environmental political controversies. This time, the debates are not only the familiar ones, such as the contested tension between economic growth and sustainability. Instead, they have a new focus on Earth system complexity, and unprecedented trade-offs in time and space.

In this chapter, I briefly summarize what some have called the 'Anthropocene debate', as well as current contentious discussions about the role of Earth system science and 'planetary boundaries' in political decision-making. I also discuss the critical role that perceptions about technological change play in this debate, and identify three overarching governance challenges (or 'puzzles') that I intend to explore in the concluding part of the book.

As I intend to show, the interesting question is not whether a new human-dominated geological era is formally here, nor whether the 
proposed transgression of 'planetary boundaries' should be reframed as 'planetary opportunities'. The truly exciting questions emerge as we try to unpack the novel institutional and political challenges that surface as humanity increases its domination over a complex Earth system.

\section{THE ANTHROPOCENE DEBATE}

Global environmental change has been on the international political agenda for decades. Some would trace it back to the first UN-led international meeting on sustainability in Stockholm 1972. As Robert Boardman argues, the origins of scientifically grounded studies of the Earth system can be traced to the eighteenth century, and especially the transformative developments in geology as a scientific discipline (Boardman 2010, p. 57).

Earth system sciences has always influenced, and been influenced by, broader social and ontological debates. In short, political, religious, cultural, institutional and other societal factors, substantially shape and frame perceptions about the Earth system (Boardman 2010, p. 71). There is no reason to believe that current notions of the Anthropocene and associated concepts such as 'planetary boundaries' are an exception. Uhrqvist and Lövbrand (2009) explore these issues in an interesting Foucauldian analysis, suggesting that Earth system science is not only a scientific endeavor, but should also be viewed as playing a key role in knowledge production and therefore in 'the formation of governmental practices' (p.3). The Earth system science community, through its methodologies, international research programs and technologies 'has made the Earth System seem stable, comparable and diagnosable and hereby open for government intervention' (p. 21).

Processes of knowledge production hence matter. My position in this discussion is different, and my main argument is that these debates should not lead us to believe that we can overlook the institutional and political implications of the human enterprise entering the Anthropocene epoch. Will Steffen, Paul Crutzen and John McNeill (2007) sum the state of knowledge elegantly:

The term [. . .] suggests that the Earth has now left its natural geological epoch, the present interglacial state called the Holocene. Human activities have become so pervasive and profound that they rival the great forces of Nature and are pushing the Earth into planetary terra incognita. The Earth is rapidly moving into a less biologically diverse, less forested, much warmer and probably wetter and stormier state. (p.614)

The notion of the Anthropocene is often traced back to earlier talks and papers by Paul Crutzen (for example, Crutzen 2002), but the proposition 
that humankind's activities are so large to effectively shape the function of the Earth system, was raised by George P. Marsh as early as the 1860s. Steffen and colleagues (2007, p. 617) suggest that human imprints on the Earth system intensified drastically after the Second World War, triggered by rapid population growth, multiple technological breakthroughs and a growing world economy. The results of these changes can be seen clearly today: in the rate of species extinction, increasing ocean acidification, rapid deforestation, exponential releases of greenhouse gases like carbon dioxide and methane, and global modification of freshwater, mineral and nutrient flows. Just to mention a few.

These might all seem like well-known and discussed global environmental issues, especially since the intense climate change debates in the early 2000s following from Al Gore's blockbuster documentary An Inconvenient Truth (2006), Sir Nicholas Stern's renowned review on the economics of climate change (2007), and the Nobel Peace Prize acknowledgement to the Intergovernmental Panel on Climate Change (2007). But the implications of the Anthropocene argument are much deeper than a familiar sense of increasing environmental stresses on planet Earth. In my mind, it is a profound insight of how human activities are shaping the Earth system. ${ }^{4}$

\section{TRANSFORMING THE PLANET}

Four considerably less known examples are illuminating illustrations of how the human enterprise is shaping Earth in astonishingly profound ways.

In 2011, Miller and colleagues published a highly controversial estimate of the global availability of wind power as limited by the kinetic (= motion) energy inherent in the Earth system (Miller et al. 2011). The novelty in this paper is its attempt to link climate impacts to wind-power extraction. Essentially, the paper calculates the unintended climate effects of proposed large-scale (17 TW) deployment of wind technologies. The calculations contain an interesting observation stylishly captured by the New Scientist: 'He [Miller] concludes that it is a mistake to assume that energy sources like wind and waves are truly renewable. Build enough wind farms to replace fossil fuels, he says, and we could seriously deplete the energy available in the atmosphere, with consequences as dire as severe climate change'. ${ }^{5}$

Human impact on biological evolution is another example. The evolution of multi-drug resistant pathogens is one of the clearest examples of how human action - through the misuse and overuse of antibiotics fundamentally changes evolutionary pressures on micro-organisms. Our impact on the rate and course of biological evolution applies across a range of species, and on global scales including biodiversity and ecosystems. 
Powerful human-induced selection pressures on species unfold through, for example, climate change as species shift geographical ranges, and compete with new species (Norberg et al. 2013, Skelly et al. 2007). In addition, humans also induce 'non-natural' exploitive selection pressure by harvesting species and individuals of certain size, morphology and behavior, thereby leaving behind 'the less desirable to reproduce and contribute genes to future generations' (Allendorf and Hard 2009, p. 9987). These humaninduced selection pressures on species not only has genetic implications (for example, causing aquatic animals such as fish to 'shrink' due to warming and fishing pressure, Forster et al. 2012), but could also potentially influence ecological dynamics on a global scale (Palkovacs et al. 2012).

Earth system scientists had also made another uncomfortable discovery. Human emission of aerosol particles into the atmosphere - through for example the combustion of fossil fuels containing sulfur - are currently masking some of the warming we would otherwise see (Steffen et al. 2007, p. 619). As many have noted, international policies to remove these health-threatening aerosols from the atmosphere, could potentially lead to rapid additional warming up to $+1^{\circ} \mathrm{C}$ (Steffen et al. 2007, p. 619, uncertainties are considerable, as some particles also contribute to warming, see Andreae et al. 2005 for a summary). ${ }^{6}$

Lastly, in 2009 a group of 28 scientists suggested that planet Earth's capacity to support human life and well-being is not only fundamentally dependent on climate regulation, but also on eight additional Earth system functions formulated as 'planetary boundaries' (elaborated in detail in Chapter 3). These 'boundaries' are nine, possibly nonlinear Earth system processes that manifest themselves at the planetary level and include in addition to climate impacts, ozone depletion, atmospheric aerosol loading, ocean acidification, global freshwater use, chemical pollution, land system change, biodiversity, and biogeochemistry (Rockström et al. 2009a, b). These 'boundaries' are not fixed, but instead rough estimates of how close to an uncertainty zone around a potential threshold that the global human community can act, without seriously challenging the continuation of the current state of the planet. ${ }^{7}$ Bluntly put: transgressing these suggested 'boundaries' could risk pushing the Earth system into a whole new equilibrium with unknown consequences for human life on the planet (see also Barnosky et al. 2012).

This recent understanding on the scale and implications of the human enterprise on biodiversity, ecosystems and the Earth system as a whole might seem overwhelming. And as I discuss below, none of these results by the scientific community translate effortlessly into policy-making, current political debates and institutional options. Two aspects complicate matters considerably. The first are the ongoing scientific debates about 
the notion of the Anthropocene, and associated concepts such as 'planetary boundaries'. The second is an emerging political debate about the usefulness and implications of the concept.

\section{THE ANTHROPOCENE AND PLANETARY BOUNDARIES - THE SCIENTIFIC DEBATE}

Have we really entered a new geological era? A quick Google search and exploration in academic databases might give the impression that the concept is well-established, yet the academic debate is far from formally settled. The 'official gate-keeper of the geological time scale' (Kolbert 2010) is neither the buzz in international media, nor the volume of academic literature using the term. Rather, it is the International Commission on Stratigraphy (ICS) headed by geologist Jan Zalasiewicz at the University of Leicester (UK).

ICS regularly debates how to name different geological time periods (Kolbert 2010). For years, geologists debated whether the Quaternary the most recent geological period commencing 2.5 million years ago ought to exist at all. The critical issue in this geological debate is whether humans can be said to have contributed to 'stratigraphically significant change' (Zalasiewicz et al. 2008, see also Zalasiewicz et al. 2010), that is a clear global signature in rocks, soils and fossil records. Hence while humanity's imprint on the Earth system might seem overwhelmingly clear through climate change, biodiversity loss and land use changes, the strength of it has been questioned from a geological temporal perspective. Will scientists millions of years in the future be able to identify a distinct layer on the Planet's sediment that matches humanity's explosive imprint on the planet? And if that were the case, when exactly would this new epoch or era have started? In the year 1800 when human population hit its first billion, or 6000 years BC when the clearing of forests for agriculture and the expansion of irrigation for rice 3000 years later led to increases in atmospheric carbon dioxide and methane concentrations has been suggested to have prevented the onset of the next ice age (Ruddiman 2003, Steffen et al. 2007, p.615)? The (stratigraphic) jury is still out.

The results from their deliberations are likely to have broader societal impacts considering emerging discussions of how to understand the wider societal implications of a human-dominated planet. The reason is that the final decision on the birth of the Anthropocene affects how risky we perceive this shift into a new epoch to be.

Clive Hamilton, professor of public ethics, as an example, argues that 
proponents of an 'early Anthropocene' whereby humans have been a planetary force since the birth of human civilization, also implicitly suggest that there is essentially 'nothing fundamentally new about the last couple of centuries of industrialism. It is in the nature of civilized humans to transform the Earth, and what is in the nature of the species cannot be resisted. [. . . ] the Anthropocene becomes in some sense natural' (Hamilton 2012, p. 3). Bluntly put: is this proposed geological transition an extremely risky anomaly in the history of planet Earth (cf. Steffen et al. 2011), or simply an extension of human societies' ingenious ability to engineer ecosystems to our species' benefit (Ellis 2012)?

As Jim Proctor (2013) notes, different and conflicting notions of what an Anthropocene future holds co-exist in current American environmental thought. At the center of this debate are different perceptions of 'nature' - what is the future of conservation and sustainability, if nature never was entirely natural, nor unnatural? And shouldn't we instead speak of the 'Obcene Epoch' to better reflect 'the layers of rubble that will pile up during the extinction of most of the plants and animals of the Holocene the ruined remains of so many of the living beings we grew up with, buried in human waste' (Dean Moore 2013).

Similar but more intense debates can be identified for the notion of 'planetary boundaries'. For example, in parallel to the publication of the paper in Nature in 2009 (Rockström et al. 2009a), Nature Climate Change invited seven experts to comment on the definition and quantification of each individual boundary. While some responses where cautiously positive, others were skeptical to the suggested quantifications, to the possibility of threshold change, and to whether the boundaries were set at the appropriate scale (in other words, global). William H. Schlesinger for example, argued that the 'threshold for nitrogen seems arbitrary and might just as easily have been set at 10 per cent or 50 per cent', noting also that defining thresholds might lead to perverse incentives for policymakers (Schlesinger 2009). Steve Bass (2009) raised similar concerns for the boundary for land use change, as did Myles Allen for the climate boundary (Allen 2009). Other criticisms related to the difficulties in defining clear global 'thresholds' for changes that have clear multi-level (global to local) and multi-system connections such as ozone depletion (Molina 2009), biodiversity (Samper 2009), and freshwater use (Molden 2009). The debate regained intensity at the end of 2012 after a paper by Brook and colleagues (2013). Their argument was - briefly put - that planetary-scale tipping points in the terrestrial biosphere were unlikely. The underlying reason is what they identify as a lack of strong interconnectivity - that is, changes in terrestrial ecosystems tend to remain localized or subcontinental events. Hence abrupt negative ecological changes, the argu- 
ment goes, are not likely to cascade and add up to planetary-scale 'tipping points'. Terry Hughes and colleagues (2013) instead focus on the temporal dimensions of threshold changes, and argues that shifts between states can be so slow (decades, centuries or longer), that they create serious early warning and response challenges. In their own words:

[W]e argue below that for systems that respond much more gradually than small lakes after transgressing a threshold, the challenge of identifying and avoiding tipping points is even greater, that is, ascertaining whether we have already crossed a threshold, are now living on borrowed time, and are shifting inexorably to a new regime. (p. 150)

Despite remaining scientific uncertainties, the attempt to define a 'safe operating for humanity' has led to an intense policy debate (elaborated below). Refinements of the identified boundaries have been suggested for phosphorus (Carpenter and Bennett 2011), freshwater use (Rockström and Karlberg 2010) and chemical pollution (Persson et al. 2013). Others, such as Steven W. Running (2012) have tried to identify additional measurable boundaries based on, for example, the terrestrial net primary production (NPP). Anthony D. Barnosky and colleagues' article 'Approaching a state shift in Earth's biosphere' takes a similar approach, and reviews the evidence for a potential abrupt change of the global ecosystem as a whole (Barnosky et al. 2012).

It should be noted that this is only a brief summary of scientific discussions within the natural sciences. Several attempts have also been made by social scientists to explore the potential implications of "planetary boundaries' for institutions and governance, including global environmental governance (Galaz et al. 2011b, Galaz et al. 2012a, b, Biermann 2012, Schmidt 2013), and national policies (Nilsson and Persson 2012). These include more interdisciplinary approaches to explore the implications of "planetary boundaries' for economic growth (Steffen et al. 2011b), and suggestions to reframe Earth system challenges as 'planetary opportunities' to bring out the adaptive and innovative capacities of societies through technology (DeFries et al. 2012, see also Westley et al. 2011).

\section{PLANETARY BOUNDARIES - THE POLITICAL DEBATE}

Political disputes about the precise temporal definition of the Anthropocene have been modest. The notion about Earth system scale 'planetary boundaries' - which are intimately linked to notions of a new human-dominated geological era - are a whole different story. While the 
original Nature paper (Rockström et al. 2009a) intentionally excluded a discussion of social drivers such as global distribution, trade, demographic change and technology in order to simplify the analysis, 'planetary boundaries' has been rapidly pulled into intense sustainability policy debates, and ideological controversies. Several examples highlight the heat in this recent debate.

Just as the world's nation states were to meet at the United Nations Conference on Sustainable Development (known as Rio+20) in June 2012, the US-based think tank Breakthrough Institute released a highly critical, and widely spread review of the 'planetary boundaries' framework (Blomqvist et al. 2012). The report questioned the underlying scientific evidence, the main results, as well as the claim that the transgression of the suggested boundaries would have detrimental implications for human well-being (Blomqvist et al. 2012, pp.4-5, see also debate in Nature between Lewis 2012 and myself in Galaz et al. 2012c).

Think tank-produced reports of this sort are overly common, but a successful spin in international media is not. The Scientific American (Biello 2012), The Economist (2012), and The Wall Street Journal (2012) all described the contents of the report. The timing was excellent from a lobbying point of view.

One of the topics on the Rio +20 agenda was a redrafted 'zero-draft' declaration, including an explicit reference to the need to stay within scientifically defined 'planetary boundaries'. This reference to the concept was later removed from the document, according to some of the negotiators involved, due to strong skepticism from amongst others the US, Chinese and G77 delegations. The main reason seems to be the perception of 'planetary boundaries' as quantified limits to growth. That is, the definition of a 'safe operating space' has, despite the authors' intent to focus on the prospects of human well-being on a planet experiencing rapid environmental change, reignited older political tensions about the need for environmental protection, and the right to development.

The perception of boundaries as limits has led to reiterated claims that 'planetary boundaries' are doomed to fail as an international policy framework as they are likely to create the same sort of political gridlock as experienced in international climate negotiations (Victor 2010). Such an argument overlooks several important developments.

One is the ambitious GEO-5 report coordinated by UNEP, and published in 2012 (UNEP 2012). GEO-5 is not only a scientific assessment of the state of the planet, but is also linked to parallel multilateral negotiation processes between member states whereby science is translated into policyrelevant messages. This translation is far from painless and requires considerable negotiations around definitions and formulations of key messages. 
The summary for policy-makers in this case, included several statements that in fact summarize key messages from the 'planetary boundaries' synthesis, without using the actual term. The first section for example, is entitled 'Critical thresholds' and states: 'The currently observed changes to the Earth System are unprecedented in human history. [. . .] As human pressures on the Earth System accelerate, several critical global, regional and local thresholds are close or have been exceeded. Once these have been passed, abrupt and possibly irreversible changes to the life-support functions of the planet are likely to occur, with significant adverse implications for human well-being' (UNEP 2012, p. 6). At Rio+20, nation states agreed on 'the continuation of a regular review of the state of the Earth's changing environment and its impact on human well-being and in this regard, we welcome such initiatives as the Global Environmental Outlook process aimed at bringing together environmental information and assessments and building national and regional capacity to support informed decision making' ('The Future We Want', \#90). Hence while 'planetary boundaries' as a concept didn't make it into the final negotiated text at Rio +20 , its main ideas in fact did: through a negotiation technical back door.

An additional debate (at the moment only in the blogosphere) has also emerged about the role of scientific advice on planetary boundaries, and associated proposals for global institutional reform. Roger Pielke Jr. (Professor at the University of Colorado at Boulder, as well as senior fellow at the Breakthrough Institute) argues that the notion of 'planetary boundaries' is associated with one political philosophy: the need for topdown interventions where 'issues of legitimacy and accountability are easily dealt with through the incontestable authority of science' ${ }^{8}$ Melissa Leach (Professor at the Institute for Development Studies, UK) as a precursor to this debate, also noted that simplified notions of planetary boundaries and interpretations emphasizing global scale urgency and crisis, have a tendency 'to align rather neatly with approaches that are top-down not bottom up, set rather than deliberated, singular rather than respectful of diversity, privileging scientific over experiential expertise, global rather than local, control rather than response-oriented, and so on' ${ }^{9}$ As I elaborate in this book, as well as in a longer blog response, I believe these to be highly simplistic notions of the governance implications of planetary boundaries. ${ }^{10}$ But Leach raises an important point worth restating, and discussing further: advocates of particular forms of authoritarian governance can use selective interpretations of 'planetary boundaries' to advance their interests. Hence it becomes essential to acknowledge, and maintain a diversity of governance perspectives (Leach 2013).

Others have instead attempted to build on, rather than question, the framework. Kate Raworth from the UK-based non-governmental 
organization Oxfam expands the 'planetary boundaries' framework to include social dimensions such as human security, social equity, and gender equality (Raworth 2012). Mark Lynas's book The God Species is an additional contribution to the debate with a strong emphasis on the role of technologies (such as nuclear power, geoengineering and genetic engineering) as a means to stay within a 'safe operating space' (Lynas 2011).

This is only the tip of the iceberg in terms of different political interpretations of the notion of a new human-dominated geological era, and 'planetary boundaries'. Several international policy initiatives have already taken off, ranging from UN-led panels and EU-documents, to meetings between religious leaders under the auspice of the Dalai Lama (Galaz et al. 2012b). These initiatives are paralleled by critical reflections, such as this quote from a blogpost by Michael Shellenberger and Ted Nordhaus (both at the Breakthrough Institute):

If the United Nations were seeking to further alienate the rapidly-growing developing world from common ecological action, it could do no better than to embrace this hoary, unscientific Malthusianism. [...]. The last thing the UN should be telling the four out of ten human beings who rely on wood and dung as their primary power sources is that we've reached the limits to human development, and technology can't save you. ${ }^{11}$

Put bluntly, even though many Earth system scientists would probably very much like to, it is practically impossible to decouple Anthropocene science and 'planetary boundaries' from its electric political context.

\section{WHAT DO WE MAKE FROM THIS?}

As the quote above illustrates, debates about the Anthropocene and proposals to keep human development within 'planetary boundaries' have, despite important differences in theoretical assumptions and methods (Rockström et al. 2009b, appendix 1, pp.4-5), clear political similarities to older disputes between Malthusians and their antagonists; controversies about the 'Limits to Growth' in the 1970s; and discussions on governance options for sustainable development since the Rio conference in 1992. Aren't debates about the implications of a new geological era just extensions of all-too-familiar debates about known sustainability issues, aged solutions, and aged lines of conflict?

An interpretation of that sort, would in my mind, be fundamentally flawed. There are four aspects in this debate that illustrate how the human enterprise's move into 'planetary terra incognita' (Steffen et al. 2007) actu- 
ally embeds some intricate and novel institutional and political challenges compared to earlier debates.

First of all, nonlinearity, 'catastrophic shifts' or 'tipping points' matter. The fact that complex social-ecological systems which underpin human well-being - such as coral reef ecosystems, agro-ecological landscapes, forests and freshwater - have the ability to shift rapidly and practically irreversibly to damaged states, add a whole different set of institutional challenges to global change. In short, 'tipping points' bring to light the need to explore the capacity of governance to facilitate early warnings, promote flexibility to changing circumstances, and support adaptive responses. This is an issue that will be explored in detail in the next chapter.

Second, scale matters. The nonlinear properties of vital social-ecological systems are not limited to local or regional scale examples. On the contrary, it has been suggested that these phenomena also characterize the behavior of the Earth system. Abrupt climate change (Alley et al. 2009), 'tipping elements' in the Earth system (Lenton et al. 2008), 'planetary boundaries' (Rockström et al. 2009b), a proposed possible 'state shift' in the Earth's biosphere (Barnosky et al. 2012), are all examples of attempts to explore the possibility of rapid, aggregated and destructive change up to the global scale. While these suggestions remain debated, the very prospect adds a layer of what I believe are unprecedented institutional requirements for governance at multiple scales.

With the future of planet Earth at stake, we should not be surprised that politics matter as well. As the previous discussion about "planetary boundaries' clearly illustrates, defining a 'safe operating space for humanity' is bound to be a controversial and politically contested topic. As social actors such as non-governmental organizations (for example, Oxfam-UK and the multi-NGO Planetary Boundaries Initiative) mobilize to reframe their activities to match the framework, other societal interests (such as the Breakthrough Institute) counter-mobilize by challenging the underlying science, and its implicit policy implications. Sustainability scientists risk being caught in the crossfire as they attempt to offer tangible connections between science and policy (for example, Steffen et al. 2011b, Biermann et al. 2012, DeFries et al. 2012, Galaz et al. 2012b). While these controversies are far from new in global environmental politics (climate change being a prime example), the electric mix between possible global 'tipping points', science, and politics should not be underestimated.

Lastly, technology matters. Allow me to elaborate on this last point as technology is a central theme of this book. 


\section{Why Technology Matters}

How do we understand Earth system 'tipping points'? Can these be measured, monitored and governed? And what novel governance mechanisms would be required to support human well-being within the 'boundaries' of the planet? These issues are - both from a scientific and political perspective-inseparable from perceptions of technological change. Simply put, technology has at least three functions in this emerging Anthropocene debate. ${ }^{12}$

First, technological advances have - at least in most parts of the world driven increased human well-being at an impressive rate. Innovations such as antibiotics for medical uses; the Haber-Bosch process which creates millions of tons of nitrogen fertilizer for agriculture each year; and information and communication technologies, are just a sample of technologies which have been critical for the 'great acceleration' and humanity's move into a new geological era. At the same time, this acceleration has not only had unintended environmental and social consequences, but could potentially push the Earth system into an extremely turbulent future as environmental stresses propagate through teleconnections (Millennium Ecosystem Assessment 2005, Adger et al. 2009, see Raudsepp-Hearne et al. 2010 for an interesting synthesis of different positions in this debate).

Second, technological innovation has been critical for our current scientific understanding of the Earth system. Rapid advances in computing power in the few last decades have not only drastically facilitated our ability to monitor and model complex Earth system processes, such as the global climate system. They have also vastly expanded the geographical scope of scientific collaborations through the explosion of information and communications technologies. As shown by the Royal Society (2011), today over 35 percent of articles published in international journals are internationally collaborative, up from 25 percent 15 years ago. Information and communication technologies are also supporting the emergence of participatory science-citizen virtual collaborations through novel information communication platforms, often denoted as 'crowdsourcing' (Wiggins and Crowston 2011).

Economist Brian Arthur's point is well suited for this context: technology is not only the result of scientific discovery; technology also lays the ground for new scientific breakthroughs (Arthur 2009). The discovery of the Higgs boson particle in particle physics, and insights about extremely complex land-ocean-climate feedbacks in the Earth system, would be impossible without the impressive advancements in computing power driven by Moore's Law. 
Third, technology is an important power, risk and cost distributer. By that I mean that technologies distribute risks and costs across time, space and social groups in ways that sometimes are difficult to predict in advance. They can be called 'quick-fixes' - technological solutions used to solve complex social-ecological problems - say, recurrent floods with higher levees. While higher levees might work initially, they also increase vulnerability and risks over time as illustrated by the devastating impacts on New Orleans by Hurricane Katrina in 2005 (Sterner et al. 2006). Distributional impacts of technologies can be profound in other ways, such as the redistribution and sometimes diffusion of power as the result of information technological change (Krasner 1991, Castells 2009). Hence technological distributions matter, and, as will be explored in this book, they pose tangible governance challenges in the Anthropocene.

Lastly, different (and often implicit) assumptions about the dynamics and direction of technological change affects how seriously different social actors perceive the risks of transgressing critical Earth system 'tipping points'. There is both a scientific and a political aspect to this. From a scientific point of view, the question is what a more explicit focus on technological change can offer to global change research agendas. DeFries and colleagues (2012) suggestion to reframe the 'planetary boundaries' as solution-oriented 'planetary opportunities', attempts to place human ingenuity and technological advances at the very center of global change research. Westley and colleagues (2011) instead suggest a stronger focus on the institutional context of innovation, and the need to explore mechanisms to steer innovation in ways that help the human enterprise to live within the 'capacity of the biosphere' (see also Leach et al. 2012, Olsson and Galaz 2012, Galaz 2012).

The political debate has a different focus, and the potential for catastrophic 'tipping points' adds an interesting dynamic (elaborated in Chapter 2). On the one hand, the potential for catastrophic shifts triggers debates about the need to rapidly develop and/or deploy technologies to put a brake on unwanted bio-geophysical changes at the global scale. Current suggestions to geoengineer the Artic to avoid devastating reinforcing climate feedbacks (such as proposed by the Artic Methan Emergency Group); to deploy large-scale protective shields for coral reefs (Rau et al. 2012); and proposals to ramp up the use of genetically modified crops and nuclear power (Lynas 2011) are all driven by concerns of the implication of global nonlinear change. Opponents, on the other hand, criticize claims about 'hard' bio-geophysical boundaries, arguing that human societies always have been able to overhaul seemingly non-negotiable physical boundaries through technological innovation. As the American ecologist Erle Ellis puts it: 
The 'planetary boundaries' hypothesis asserts that biophysical limits are the ultimate constraints on the human enterprise. Yet the evidence shows clearly that the human enterprise has continued to expand beyond natural limits for millennia. Indeed, the history of human civilization might be characterized as a history of transgressing natural limits and thriving. (Ellis 2012)

Diamandis and Kotler (2012) make a similar argument with an explicit focus on the potential of exponential development in technologies such as nanotechnology and synthetic biology, and additional changes in the global innovation landscape such as Do-It-Yourself-Innovators and billionaire techno-philanthropists such as Bill Gates and Richard Branson. In short, an analysis about governance and politics in the Anthropocene simply cannot afford to ignore the role of technological change.

\section{CONCLUSION}

The Anthropocene and associated scientific hypotheses such as 'planetary boundaries' are messy, socially contested, and scientifically debated. This, however, does not render these concepts useless to study from an institutional and governance perspective. Earth system science has always been debated. Geologists in the eighteenth century not only expanded our evidence-based understanding of the behavior of our planet, they also challenged deeply held religious beliefs about the Earth (Boardman 2010). In the beginning of the 1900s, the scientific suggestion that Earth was covered by slowly moving crustal plates (today known as plate tectonics), was widely challenged and debated by scholars and intellectuals.

This latter example is not intended as a harsh, populist argument against constructive criticism summarized earlier. Instead, it should be seen as a modest call to appreciate existing controversies about the Anthropocene and 'planetary boundaries' as a normal state of scientific discovery. Scientific theories evolve over time because they are debated, not the other way around.

My personal view in this debate, and in this book, is the following. While there certainly are areas of strong disagreement, few global change scholars would question the claim that humanity has entered a new era of rapid environmental change. The human enterprise has drastically changed Earth's climate dynamics, fundamentally modified marine and land-based ecosystems at very large scales, and even changed the course of biological evolution. These changes, in combination with insights about how complex systems behave, pose extremely challenging risks at unprecedented temporal and spatial scales. The rest of this book will build on this insight (or assumption, depending on where you stand in the debate). 
The critical question therefore is not whether the Anthropocene from a stratigraphic perspective is here, or whether global 'boundaries' make sense at local and regional scales. Nor is it whether the proposed transgression of Earth system 'tipping points' could lead to global collapse, or instead indicate tremendous 'planetary opportunities'. The critical and interesting questions - at least for me as a political scientist - are what this new Anthropocene debate brings to existing political discussions about global change, sustainability and governance. And how to analytically engage with the novel institutional and political challenges that emerge as humanity increases its domination over a complex Earth system. This issue is discussed in the next chapter. 